Supporting Information for

\title{
Redox- and pH-responsive orthogonal supramolecular self-assembly: An ensemble displaying molecular switching characteristics
}

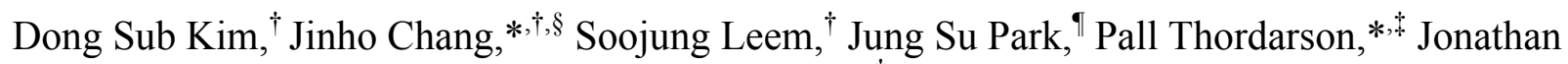
L. Sessler* ${ }^{\dagger}$

${ }^{\dagger}$ Department of Chemistry, 105 East 24th Street, Stop A5300, The University of Texas at Austin, Austin, Texas 78712-1224, United States

${ }^{\S}$ Department of Chemistry, Sungshin W. University, 55 Dobong-ro, 76 ga-gil, Gangbuk-gu, Seoul 142732, Republic of Korea

`Department of Chemistry, Sookmyung Woman’s University, Seoul 140-742, Korea

${ }^{\ddagger}$ School of Chemistry, The University of New South Wales, Sydney, NSW 2052, Australia.

*Corresponding authors: jinho_echem@sungshin.ac.kr; p.thordarson@unsw.edu.au;

sessler@cm.utexas.edu

\section{Contents}

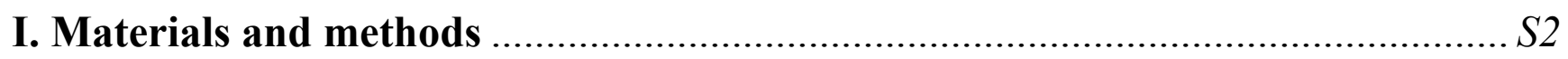

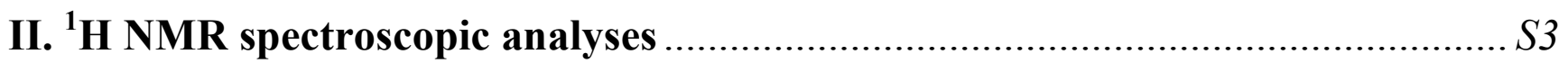

III. UV-Vis spectroscopic analyses and binding models ................................... 66

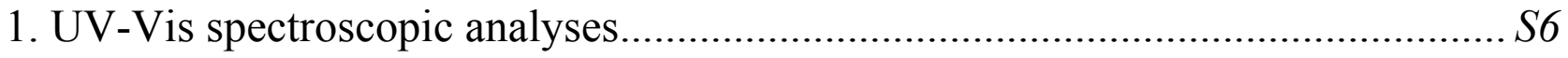

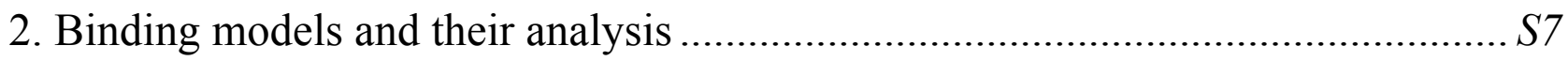

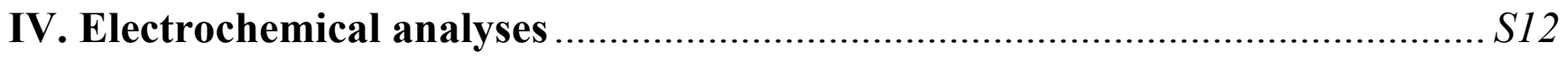

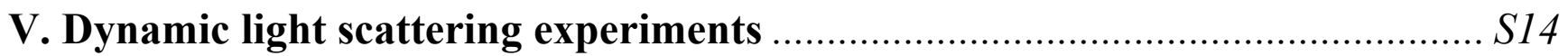

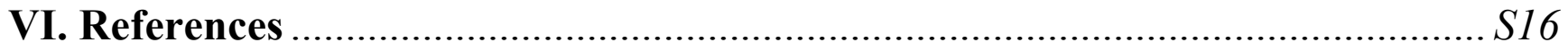




\section{Materials and methods}

All reagents were purchased from Aldrich and used without further purification. Compounds $\mathbf{1}$ and $\mathbf{2}$ were prepared according to reported procedures. ${ }^{1,2}$ Except where noted, all measurements were performed in a mixture of $\mathrm{CH}(\mathrm{D}) \mathrm{Cl}_{3}, \mathrm{CS}_{2}(7: 3, \mathrm{v} / \mathrm{v})$ containing a trace amount of (deuterated) DMSO so as to overcome the limited solubility of compound 2. 1D ${ }^{1} \mathrm{H}, 2 \mathrm{D}{ }^{1} \mathrm{H}$ ROESY and DOSY NMR spectra were recorded at $25^{\circ} \mathrm{C}$ using $400 \mathrm{MHz}$ Agilent MR or $600 \mathrm{MHz}$ Varian DirectDrive instruments. DOSY spectra were referenced relative to $\mathrm{D}_{2} \mathrm{O} / \mathrm{H}_{2} \mathrm{O}$ at $25{ }^{\circ} \mathrm{C}$. UV-Vis spectra were recorded from 400 to 800 nm using a Varian Cary 5000 spectrophotometer at room temperature. For the spectral titrations, changes in spectral signature were monitored at one or more wavelengths as a function of the appropriate parameter (concentration, mole fraction, etc.). Unless otherwise indicated, a cell length of 10 mm was used for all UV-Vis spectral studies. Cyclic voltammetry (CV) measurements were carried out at ambient temperature using a CV-50W voltammetric analyzer (BAS). All CV measurements were performed with three electrodes at room temperature, namely a glassy carbon working electrode, a Pt wire counter electrode, and an $\mathrm{Ag} / \mathrm{AgCl}$ couple as the reference electrode. All solutions were purged with nitrogen for $5 \mathrm{~min}$ before each electrochemical experiment. A scan rate of $10 \mathrm{mV} / \mathrm{s}$ was employed for all measurements. For spectroelectrochemical analyses, a Pt mesh working electrode, a Pt wire counter electrode, and a $\mathrm{Ag} / \mathrm{AgCl}$ reference electrode were used. The diffusion coefficients, $D$, of $\mathrm{SPr}-$ TTF-pyrrole, $\mathbf{3}^{3}$ and $\mathbf{1}$ were measured by chronoamperometry on a Au microelectrode (radius, $a=50$ $\mu \mathrm{m}) .{ }^{4}$ For this measurement, a $\mathrm{CH} 900$ potentiostat (CH Instrument, TX) was used. Dynamic light scattering (DLS) was conducted with a Wyatt DynaPro NanoStar equipped with a $100 \mathrm{~mW}, 662 \mathrm{~nm}$ airlaunched laser and a detector at a constant angle of $90^{\circ}$. 


\section{II. ${ }^{1} \mathrm{H}$ NMR spectroscopic analyses}

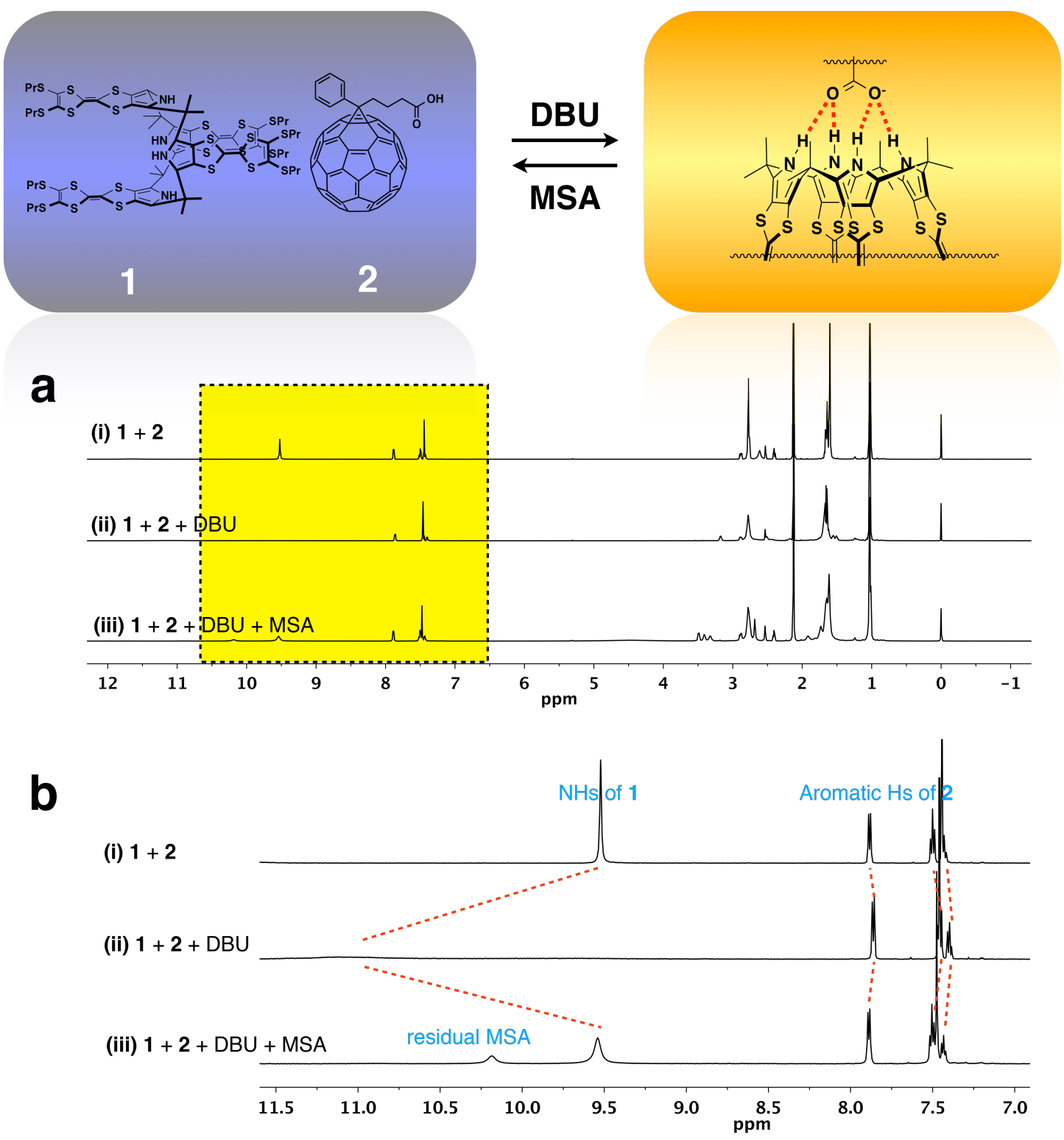

Figure S1. (a) Full-scale ${ }^{1}$ H NMR spectra of (i) an equimolar mixture of 1 and 2 (2 mM each), (ii) the mixture of (i) with 3 equiv of 1,8-diazabicyclo[5.4.0]undec-7-ene (DBU), and (iii) the mixture of (ii) upon addition of 3 equiv of methanesulfonic acid (MSA) in the solvent system described in the Materials and Methods section. (b) Partial views of these same ${ }^{1} \mathrm{H}$ NMR spectra highlighting the signals for the NH protons of $\mathbf{1}$ and the aromatic protons of $\mathbf{2}$ and the changes observed upon sequential addition of DBU and MSA. 

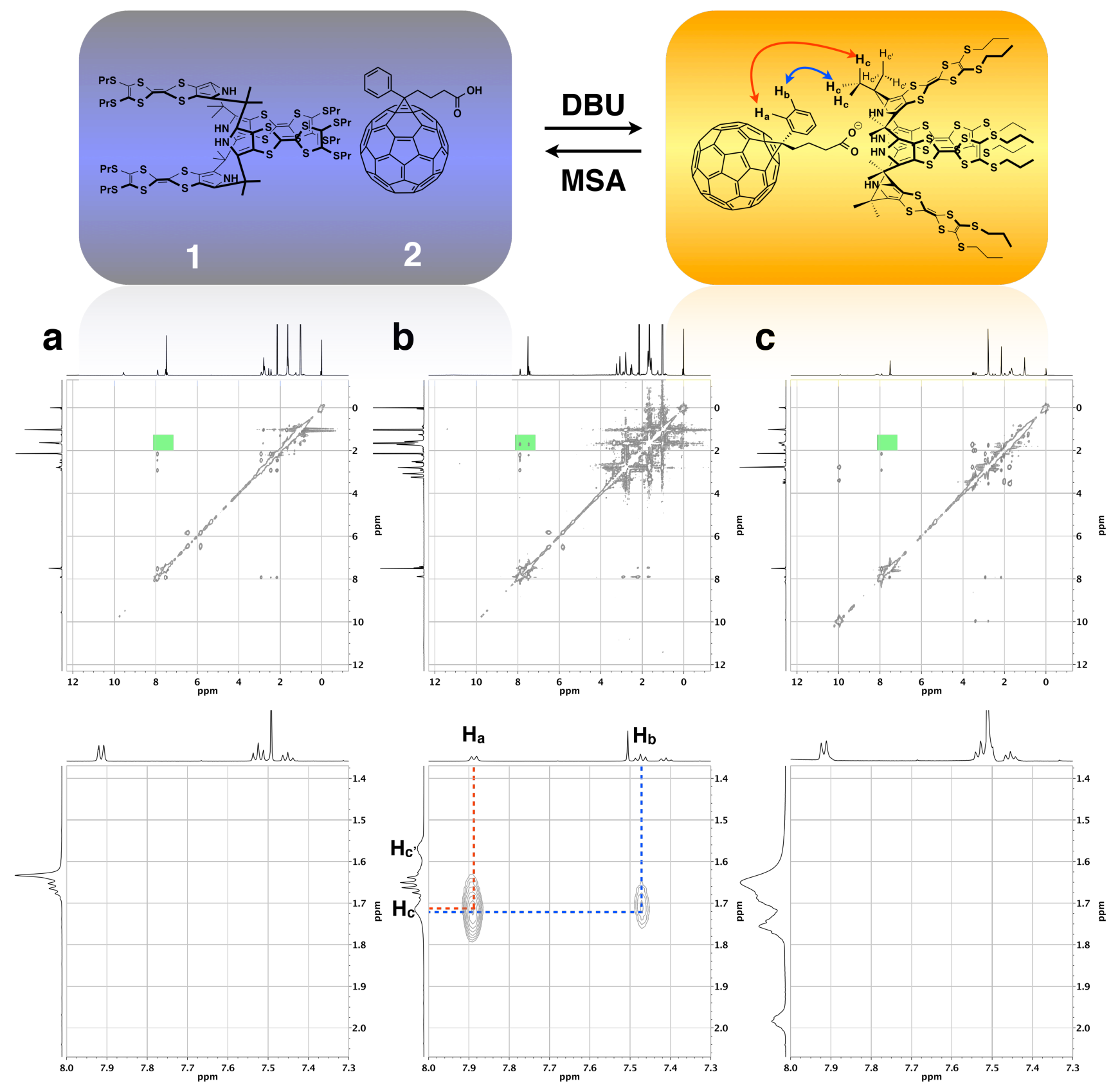

Figure S2. Full (top) and expanded (bottom) view of the 2D ${ }^{1} \mathrm{H}$ ROESY NMR spectra of (a) $\mathbf{1}+\mathbf{2}$ (2 $\mathrm{mM}$ each), (b) $\mathbf{1}+\mathbf{2}+3.0$ molar equiv of DBU, and (c) the spectra shown in (b) +3.0 equiv of MSA. All spectra were recorded in the solvent system described in the Materials and Methods section. 
Evidence that the addition of tetrabutylammonium fluoride, a source of a highly competitive anion, could be used to promote disassembly of the self-assembled structure came from diffusion ordered NMR spectroscopic analyses. In particular, the diffusion coefficients of proton signals corresponding to thiopropyl group in 1 increase from $1.45 \times 10^{-9} \mathrm{~m}^{2} / \mathrm{s}$ to $1.65 \times 10^{-9} \mathrm{~m}^{2} / \mathrm{s}$ (Figure $\mathrm{S} 3$ ).
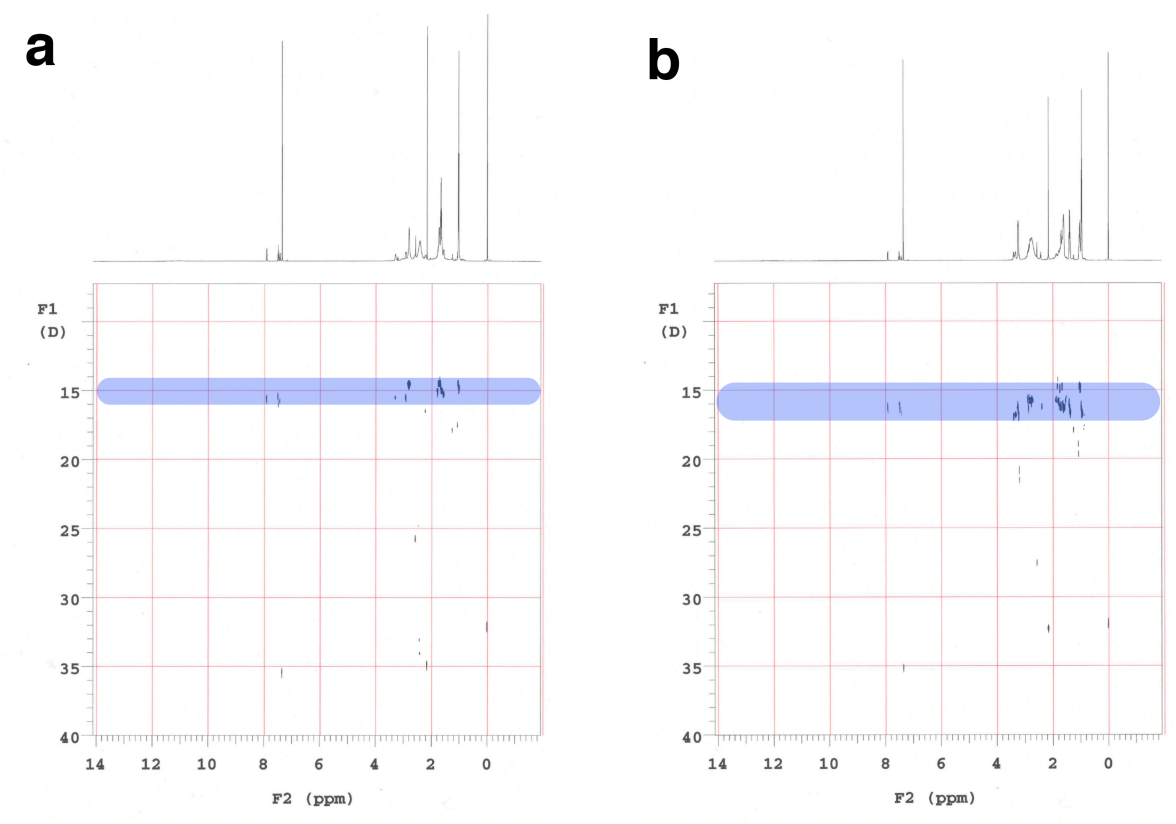

Figure S3. 2D ${ }^{1} \mathrm{H}$ DOSY NMR spectra of solutions containing 1 and 2 (2 $\mathrm{mM}$ each) recorded in the presence of (a) DBU (1.5 equiv) and (b) DBU (1.5 equiv) and TBAF (3 equiv). All spectra were recorded in the solvent system described in the Materials and Methods section. 

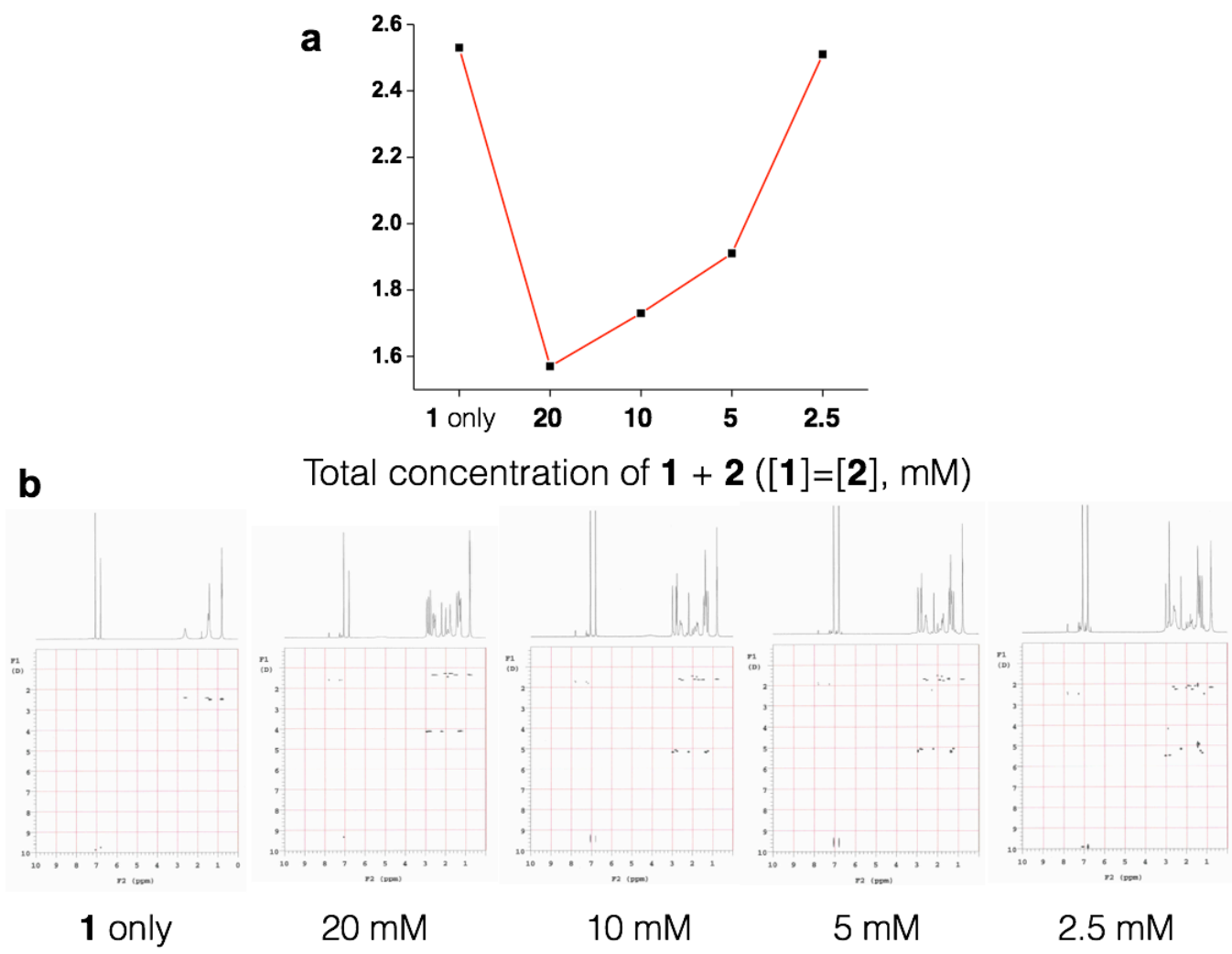

Figure S4. (a) Change in the diffusion coefficient D (plotted as Y-axis) as a function of concentration (X-axis) from ${ }^{1} \mathrm{H}$ DOSY NMR studies carried out in $o$-dichlorobenzene. The data points in (a) are the mean values of the diffusion coefficients recorded for the phenyl protons of 2 at each concentration where an analysis was made. (b) Spectra of an equimolar mixture of $\mathbf{1}$ and $\mathbf{2}$ recorded as a function of overall concentration in $o$-dichlorobenzene. Individual measurements were recorded upon diluting a solution of $\mathbf{1}+\mathbf{2}$ wherein the initial concentration of the individual components, $\mathbf{1}$ and $\mathbf{2}$, were each 10 $\mathrm{mM}$. All samples were recorded in the presence of 3 molar equiv of DBU. 


\section{UV-Vis spectroscopic analyses and binding models}

\section{UV-Vis spectroscopic analyses}
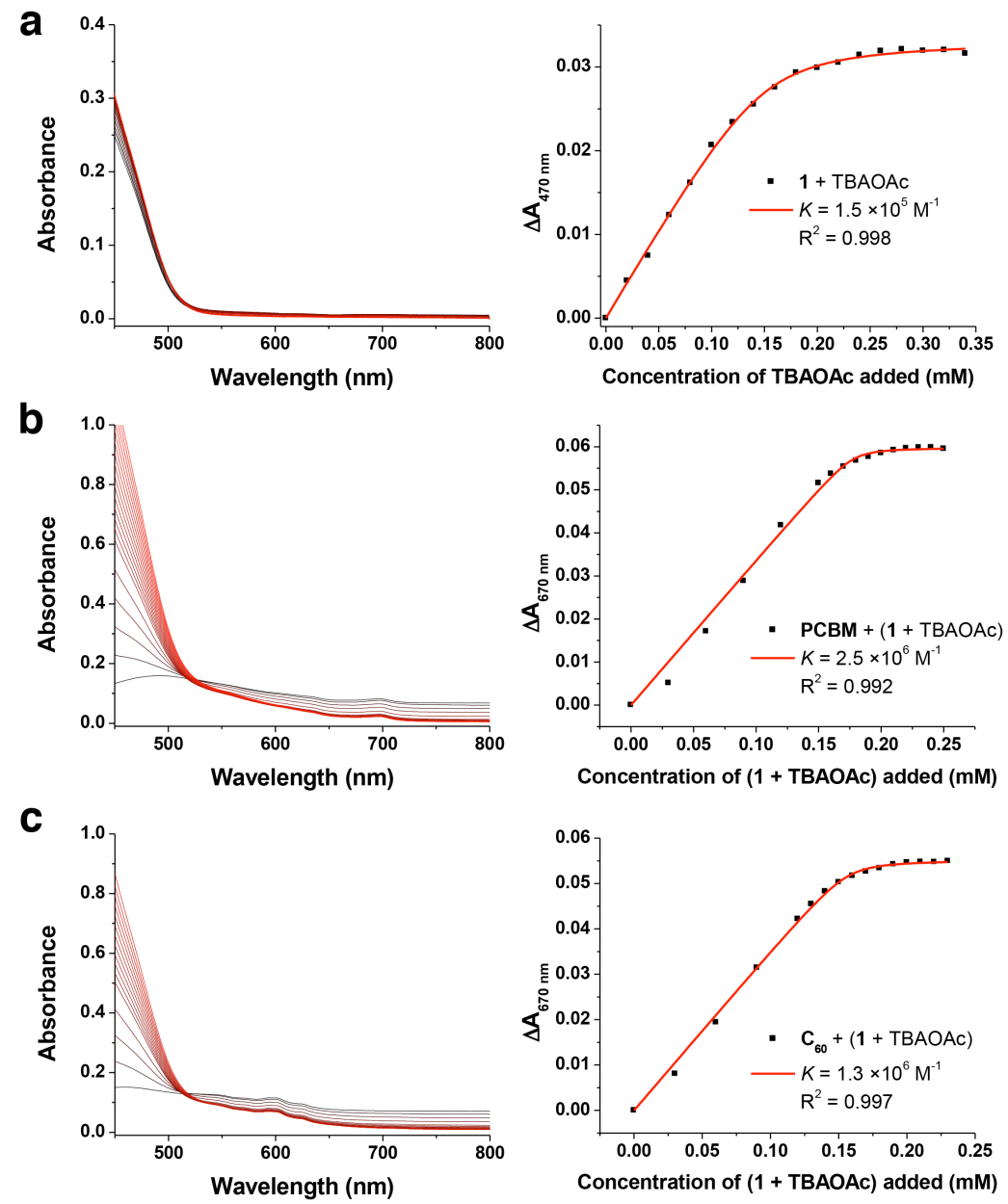

Figure S5. (a) Changes in the electronic spectrum of $1(100 \mu \mathrm{M})$ seen upon the incremental addition of TBAOAc (tetrabutylammonium acetate) in the solvent system described in the Materials and Methods section (left) and the corresponding binding isotherm analysis (right). (b) Changes in the electronic spectrum of phenyl $\mathrm{C}_{61}$ butyric acid methyl ester (PCBM, $\left.50 \mu \mathrm{M}\right)$ seen upon the incremental addition of $(1+$ TBAOAc) in the solvent system described in the Materials and Methods section (left) and the corresponding binding isotherm analysis (right). (c) Changes in the electronic spectrum of $\mathrm{C}_{60}(50 \mu \mathrm{M})$ seen upon the incremental addition of $(1+$ TBAOAc $)$ in the solvent system described in the Materials and Methods section (left) and the corresponding binding isotherm analysis (right). 

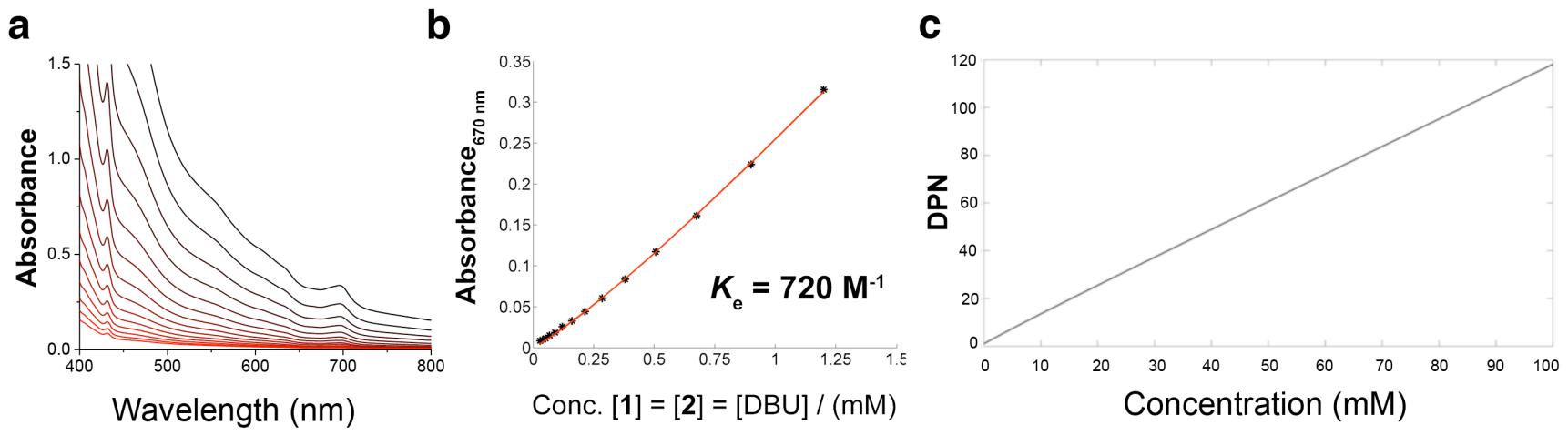

Figure S6. (a) Electronic spectra recorded upon sequential dilution of a solution containing equimolar quantities of 1, 2, and DBU in the solvent system described in the Materials and Methods section, (b) corresponding binding analysis, and (c) simulated plot showing the degree of polymerization.

\section{Binding models and their analysis}

\section{i) Overall approach:}

The association constant $\left(K_{\mathrm{a}}\right)$ for the binding of $(2+\mathrm{DBU})+\mathbf{1}$ and the aggregation or equilibrium constant $\left(K_{\mathrm{e}}\right)$ for the aggregation of the complex $(2+\mathrm{DBU}) \cdot \mathbf{1}$ were obtained via a two-step process that builds on an approach outlined by Hamelin and Jullien. ${ }^{5}$ The first step involved obtaining $K_{\mathrm{a}}$ from a simple 1:1 binding model using data from the titration of $(\mathbf{2}+\mathrm{DBU})$ with $\mathbf{1}$ (Figure $3 \mathrm{~A}$ and Figure $3 \mathrm{C})$. The resulting $K_{\mathrm{a}}$ was then used in fitting the data from the sequential dilution studies involving equimolar quantities of 1, 2 and DBU (Figure S6) to an aggregation model from Hamelin and Jullien ${ }^{5}$ to obtain $K_{\mathrm{e}}$. In both cases, a custom written Matlab program similar to one published previously ${ }^{6}$ was used to perform a global analysis of the UV-Vis data in the region between 550-800 $\mathrm{nm}$.

\section{ii) Obtaining $K_{\mathrm{a}}$ :}

The data from the titration of $(2+\mathrm{DBU})$ with 1 was fitted to a simple 1:1 binding model to obtain $K_{\mathrm{a}}$ according to equations (S1) and (S2) using a custom written non-linear regression Matlab program ${ }^{7}$ slightly modified from earlier work. ${ }^{6}$

$$
[\mathrm{HG}]=\left(\frac{1}{2}\left\{\left([\mathrm{G}]_{0}+[\mathrm{H}]_{0}+\frac{1}{K_{\mathrm{a}}}\right)-\sqrt{\left([\mathrm{G}]_{0}+[\mathrm{H}]_{0}+\frac{1}{K_{\mathrm{a}}}\right)^{2}+4[\mathrm{H}]_{0}[\mathrm{G}]_{0}}\right\}\right)
$$




$$
\mathrm{A}=\varepsilon_{\mathrm{H}}\left([\mathrm{H}]_{0}-[\mathrm{HG}]\right)+\varepsilon_{\mathrm{HG}}([\mathrm{HG}])
$$

where $[\mathrm{HG}]=$ concentration of 1:1 host-guest complex, $[\mathrm{H}]_{0}$ and $[\mathrm{G}]_{0}$ the total (initial) concentration of the host and guest, respectively, $K_{\mathrm{a}}=(1: 1)$ association constant, $\mathrm{A}=$ absorbance, $\varepsilon_{\mathrm{H}}=$ molar absorptivity of the free host and $\varepsilon_{\mathrm{HG}}=$ molar absorptivity of the 1:1 host-guest complex.

\section{iii) Obtaining $K_{\mathrm{e}}$ :}

The approach used here is based on the work by Hamelin and Jullien ${ }^{5}$ and starts by defining the following two equilibria according to equations (S3) and (S4):

$$
\begin{aligned}
& K_{\mathrm{a}}=\frac{[\mathrm{HG}]}{[\mathrm{H}][\mathrm{G}]} \\
& K_{\mathrm{e}}=\frac{\left[(\mathrm{HG})_{j+1}\right]}{[\mathrm{HG}]\left[(\mathrm{HG})_{j}\right]}
\end{aligned}
$$

Here $K_{\mathrm{e}}=$ aggregation or equilibrium constant, $[\mathrm{HG}]_{j}=$ concentration of the aggregated complex HG with degree of polymerization $=j$.

From these two equations Hamelin and Jullien ${ }^{5}$ showed that if the concentrations of the host and guest are equal $\left([\mathrm{H}]_{0}=[\mathrm{G}]_{0}\right)$, as is the case in the sequential dilution study shown in Figure S5, the concentration of the free host $[\mathrm{H}]$ (equal to $[\mathrm{G}]$ ) can be obtained from the quintic $\left(5^{\text {th }}\right.$ order) equation $(\mathrm{S} 5)^{5}$ :

$$
[\mathrm{H}]^{5}\left\{\left(K_{\mathrm{a}}\right)^{2}\left(K_{\mathrm{e}}\right)^{2}\right\}-[\mathrm{H}]^{4}\left\{\left(K_{\mathrm{a}}\right)^{2}\left(K_{\mathrm{e}}\right)^{2}[\mathrm{H}]_{b}\right\}-[\mathrm{H}]^{3}\left\{2 K_{\mathrm{a}} K_{\mathrm{e}}[\mathrm{H}]_{0}\right\}+[\mathrm{H}]^{2}\left\{2 K_{\mathrm{a}} K_{\mathrm{e}}[\mathrm{H}]_{0}+K_{\mathrm{a}}\right\}+[\mathrm{H}]-[\mathrm{H}]_{0}=0
$$

This equation could not be solved numerically without fixing $K_{\mathrm{a}}$ first and hence reducing the number of unknown parameters to one $\left(K_{\mathrm{e}}\right)$. As explained by Hamelin and Jullien ${ }^{5}$ and mentioned in the main text of this paper, the assumption that $K_{\mathrm{a}}$ can be estimated from the titration of $\mathrm{H}$ with $\mathrm{G}$ (here $2+\mathrm{DBU}$ with $\mathbf{1}$ ) is valid provided $K_{\mathrm{e}}<K_{\mathrm{a}}$, as is the case here.

The $K_{\mathrm{a}}$ value obtained earlier $\left(K_{\mathrm{a}}=1722 \mathrm{M}^{-1}-\right.$ Figure $\left.3 \mathrm{C}\right)$ was therefore used in fitting the experimental data to the binding model based on equation (S5). The non-linear regression process starts by using an initial guess for the $K_{\mathrm{e}}$ and the $K_{\mathrm{a}}$ value above. These are then passed to the subroutine fivedeg in Matlab that was written to solve this quintic equation using the roots function: 


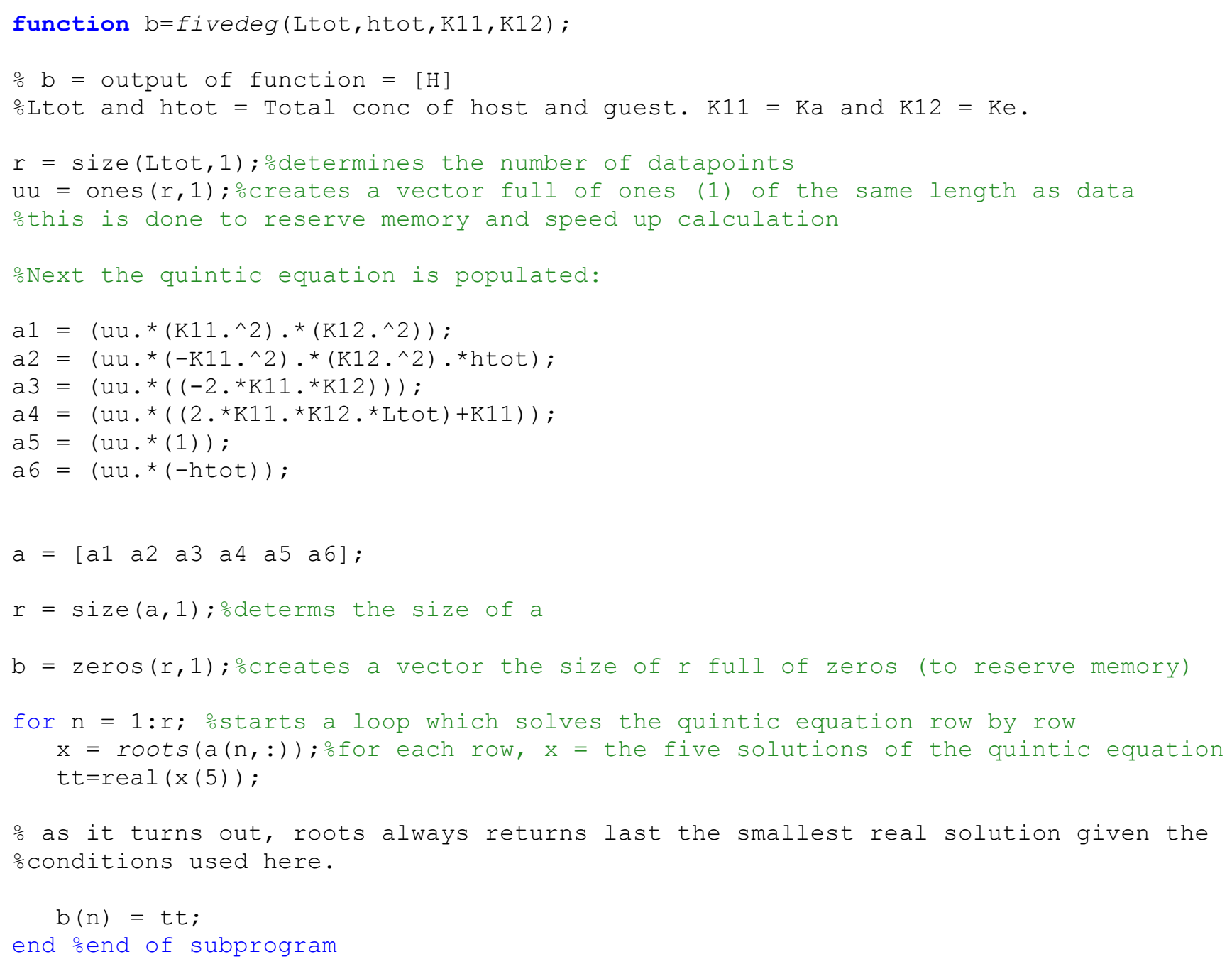

The output of this function was then used to calculate $[\mathrm{H}]$ and from that, $[\mathrm{HG}]$ as $[\mathrm{HG}]=[\mathrm{H}]_{0}-[\mathrm{H}]$. The absorbance (A) was then calculated according to equation (S2) above from [H] and [HG] using the left hand matrix division (linear regression) function in Matlab. Iteration using the Simplex algorithm (fminsearch in Matlab) then yielded $K_{\mathrm{e}}=720 \mathrm{M}^{-1}$ after converging to the set level of tolerance $\left(<10^{-18}\right.$ ).

\section{iv) Obtaining DPN:}

The degree of polymerization; DPN (Figure S5c) was obtained from a modified version of the Carother's equation (S6):

$\mathrm{DPN}=\frac{1}{1-p}$ 
Here $p=$ mole fraction of monomers that have polymerized. It follows in simple aggregating systems with equimolar concentration of the building blocks such as in the present case, that the mole fraction of the free (non-aggregated) species $[\mathrm{H}] \alpha=[\mathrm{H}] /[\mathrm{H}]_{0}=1-p$. Hence, equation (S6) can be rearranged to give equation (S7):

$\mathrm{DPN}=\frac{1}{1-p}=\frac{1}{\alpha}=\frac{[\mathrm{H}]_{0}}{[\mathrm{H}]}$

When $K_{\mathrm{a}}, K_{\mathrm{e}},[\mathrm{H}]_{0}$ and $[\mathrm{G}]_{0}$ are known, $[\mathrm{H}]$ can be calculated from equation (S5). DPN can thus be obtained from equation (S7) as shown in Figure S6c. 


\section{Electrochemical analyses}

SPr-TTF-C[4]P 1 is a teterapyrrolic macrocyclic compound that consists of four TTF-functionalized pyrroles $3^{3}$. To optimize conditions under which 1 is fully oxidized to its octa-cationic species $\left(2 \mathrm{e}^{-}\right.$from each TTF unit $\times 4$ ) without decomposition of the medium, the redox behavior of the known ${ }^{3}$ monomer 3 (structure shown in Figure S7b) was also studied.

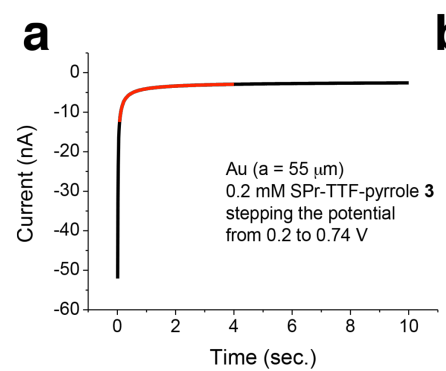

C

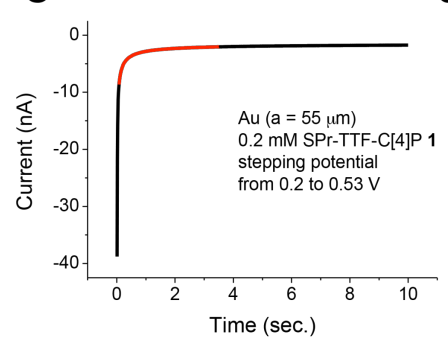

b

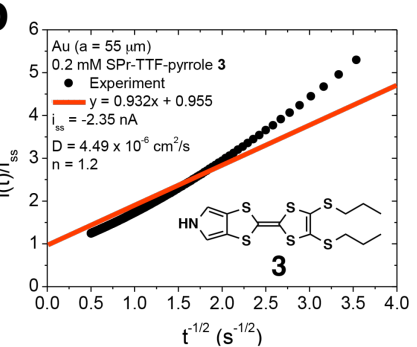

d

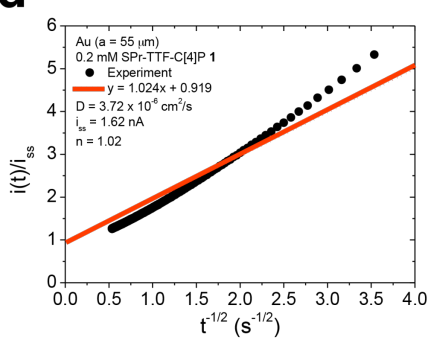

e

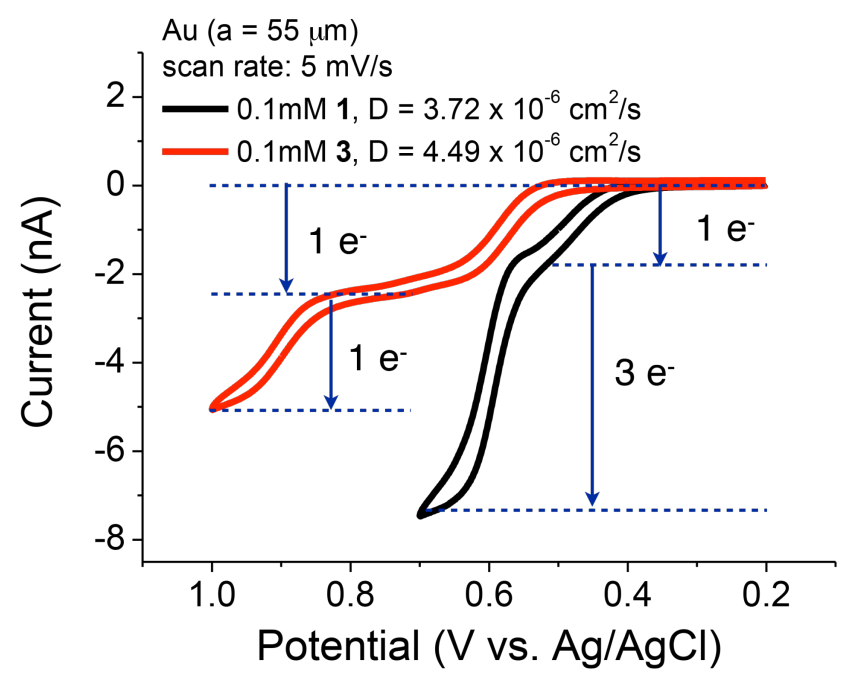

Figure S7. Chronoamperograms measured by stepping the potential (a) from 0.2 to $0.74 \mathrm{~V}$ for $10 \mathrm{~s}$ (black) for a $0.2 \mathrm{mM}$ solution of $\mathbf{3}^{3}$ (c) from 0.2 to $0.53 \mathrm{~V}$ in $0.2 \mathrm{mM}$ of $\mathbf{1}$ in the solvent system described in the Materials and Methods section. (b) and (d) plot of $i(\mathrm{t}) / i_{\mathrm{ss}}$ vs. $t^{-1 / 2}$ obtained from the current region marked with a red line in panels (a) and (c), respectively. (e) Cyclic voltammograms (CVs) measured in $0.1 \mathrm{mM}$ of $\mathbf{1}$ (black) and the same concentration of $\mathbf{3}$ (red) on a Au UME with radius of $55 \mu \mathrm{m}$ at $5 \mathrm{mV} / \mathrm{s}$, respectively. All experiments were performed in the solvent mixtrue described in the Materials and Methods section but containing $0.1 \mathrm{M}$ tetrahexylammonium tetrafluoroborate $\left(\mathrm{THABF}_{4}\right)$ as a supporting electrolyte. 

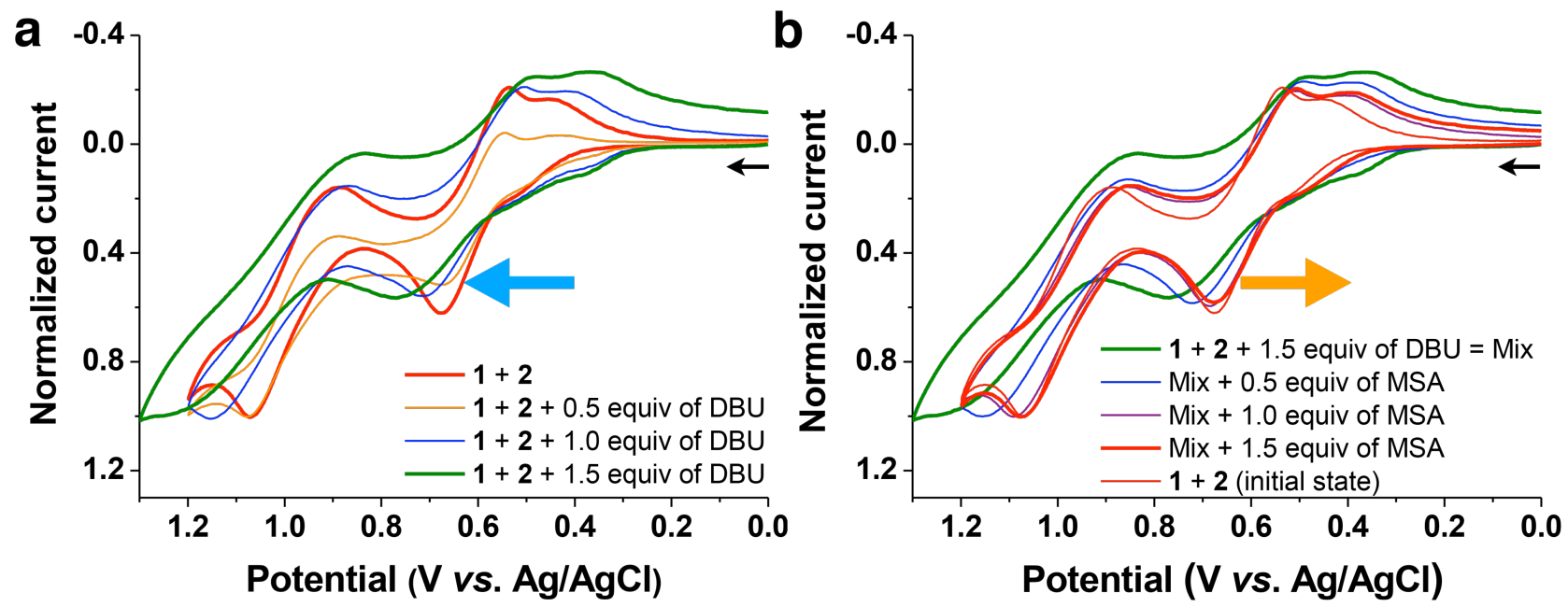

Figure S8. Full view of cyclic voltammograms recorded upon the sequential addition of (a) DBU and (b) MSA to a mixture of $\mathbf{1}$ and $\mathbf{2}$ in the solvent system detailed in the Materials and Methods section but containing $\mathrm{THABF}_{4}(0.1 \mathrm{M})$ as the supporting electrolyte. The measurements in question were performed with a $\mathrm{Pt}$ counter electrode, a $\mathrm{Ag} / \mathrm{AgCl}$ reference electrode, and a glassy carbon working electrode. 


\section{Dynamic light scattering (DLS) experiments}

Table S1. Formation and deformation of oligomers by acid/base chemistry

\begin{tabular}{|c|c|c|c|c|c|c|c|c|c|c|}
\hline \multirow{7}{*}{$\mathrm{PCBA}+\mathrm{DBU}$} & & Item & $\begin{array}{c}\text { Time } \\
\text { (s) }\end{array}$ & $\begin{array}{c}\text { Temp } \\
\text { (C) }\end{array}$ & $\begin{array}{c}\text { Intensity } \\
\text { (Cnt/s) }\end{array}$ & $\begin{array}{c}\text { Radius } \\
\text { (nm) }\end{array}$ & $\%$ Pd & Mw-R (kDa) & Amp & Baseline \\
\hline & Mean & --- & --- & 25 & $6.1 \mathrm{E} 5$ & 2.0 & 0 & 26 & 0.16 & 1.01 \\
\hline & $\mathbf{S}$ & --- & --- & 0 & $1.5 \mathrm{E} 5$ & 1.1 & 0 & 32 & 0.07 & 0.01 \\
\hline & $\% S$ & --- & --- & 0 & 24.1 & 55.5 & --- & 122 & 43.5 & 1.13 \\
\hline & $\mathbf{S}^{2}$ & --- & --- & 0 & 2.2E10 & 1.3 & 0 & 1045 & 0.01 & 0 \\
\hline & Min & --- & --- & 25 & 4.0E5 & 0.0 & 0 & 0 & 0 & 1 \\
\hline & $\operatorname{Max}$ & --- & --- & 25 & 9.3E5 & 4.9 & 0 & 136 & 0.36 & 1.04 \\
\hline
\end{tabular}

\begin{tabular}{|c|c|c|c|c|c|c|c|c|c|c|}
\hline \multirow{7}{*}{$\begin{array}{c}\text { PCBA + DBU } \\
+ \\
\text { TTF-C[4]P }\end{array}$} & & Item & $\begin{array}{c}\text { Time } \\
\text { (s) }\end{array}$ & $\begin{array}{l}\text { Temp } \\
\text { (C) }\end{array}$ & $\begin{array}{c}\text { Intensity } \\
\text { (Cnt/s) }\end{array}$ & $\begin{array}{c}\text { Radius } \\
\text { (nm) }\end{array}$ & $\% \mathrm{Pd}$ & Mw-R (kDa) & Amp & Baseline \\
\hline & Mean & --- & --- & 25 & $6.5 \mathrm{E} 6$ & 52.5 & 0 & 51400 & 0.08 & 1.04 \\
\hline & s & --- & --- & 0 & 1.0E6 & 29.0 & 0 & 54300 & 0.02 & 0.02 \\
\hline & $\% S$ & --- & --- & 0 & 16.0 & 55.2 & 103.3 & 105 & 30.75 & 1.56 \\
\hline & $\mathbf{S}^{2}$ & --- & --- & 0 & 1.1E12 & 838.7 & 0 & 2.94E9 & 0.001 & 0 \\
\hline & Min & --- & --- & 25 & 5.0E5 & 0.0 & 0 & 0 & 0 & 1 \\
\hline & Max & --- & --- & 25 & 8.3E6 & 108.6 & 0.1 & 195000 & 0.11 & 1.07 \\
\hline
\end{tabular}

\begin{tabular}{|c|c|c|c|c|c|c|c|c|c|c|}
\hline \multirow{7}{*}{$\begin{array}{c}\text { PCBA + DBU + } \\
\text { TTF-C[4]P + } \\
\text { MSA }\end{array}$} & & Item & $\begin{array}{c}\text { Time } \\
\text { (s) }\end{array}$ & $\begin{array}{l}\text { Temp } \\
\text { (C) }\end{array}$ & $\begin{array}{l}\text { Intensity } \\
\text { (Cnt/s) }\end{array}$ & $\begin{array}{c}\text { Radius } \\
\text { (nm) }\end{array}$ & $\% P d$ & Mw-R (kDa) & Amp & Baseline \\
\hline & Mean & --- & --- & 25 & 8.9E6 & 19.4 & 16.1 & 11300 & 0.04 & 1.02 \\
\hline & $\mathbf{s}$ & --- & --- & 0 & 1.9E6 & 22.9 & 17.1 & 19500 & 0.02 & 0.01 \\
\hline & $\% \mathrm{~S}$ & --- & --- & 0 & 21.5 & 118.2 & 106.7 & 173 & 41.74 & 1.26 \\
\hline & $\mathbf{S}^{2}$ & --- & --- & 0 & 3.6E12 & 525.2 & 293.1 & 3.81E8 & 0 & 0 \\
\hline & Min & --- & --- & 25 & 5.1E6 & 0.0 & 0 & 0 & 0 & 1 \\
\hline & Max & --- & --- & 25 & 1.3E7 & 73.4 & 48.2 & 78100 & 0.08 & 1.05 \\
\hline
\end{tabular}


Table S2. Concentration dependent studies; the total concentration refers to [1] + [2].

\begin{tabular}{|c|c|c|c|c|c|c|c|c|c|c|}
\hline \multirow{7}{*}{$\begin{array}{c}\text { PCBA + DBU } \\
+ \\
\text { TTF-C[4]P } \\
\text { Total } \\
\text { concentration } \\
20 \mathrm{mM}\end{array}$} & & Item & $\begin{array}{c}\text { Time } \\
\text { (s) }\end{array}$ & $\begin{array}{c}\text { Temp } \\
\text { (C) }\end{array}$ & $\begin{array}{c}\text { Intensity } \\
\text { (Cnt/s) }\end{array}$ & $\begin{array}{c}\text { Radius } \\
\text { (nm) }\end{array}$ & $\% P d$ & Mw-R (kDa) & Amp & Baseline \\
\hline & Mean & --- & --- & 25 & 1.4E6 & 198.3 & 13 & 1.11E7 & 0.56 & 1.08 \\
\hline & $\mathrm{s}$ & --- & --- & 0 & 2.6E6 & 483.3 & 12.8 & 4.18E7 & 0.20 & 0.12 \\
\hline & $\% S$ & --- & --- & 0 & 1.9 & 243.7 & 98.2 & 377 & 35.02 & 10.66 \\
\hline & $\mathbf{S}^{2}$ & --- & --- & 0 & $6.5 \mathrm{E} 10$ & 2.3E5 & 162.7 & $1.75 \mathrm{E} 15$ & 0.038 & 0.013 \\
\hline & Min & --- & --- & 25 & 1.1E6 & 24.9 & 0 & 6240 & 0.40 & 0.94 \\
\hline & Max & --- & --- & 25 & 2.3E6 & 2037.1 & 23.8 & 1.86E8 & 1.06 & 1.48 \\
\hline
\end{tabular}

\begin{tabular}{|c|c|c|c|c|c|c|c|c|c|c|}
\hline \multirow{7}{*}{$\begin{array}{c}\text { PCBA + DBU } \\
+ \\
\text { TTF-C[4]P } \\
\text { Total } \\
\text { concentration } \\
10 \mathrm{mM}\end{array}$} & & Item & $\begin{array}{l}\text { Time } \\
\text { (s) }\end{array}$ & $\begin{array}{l}\text { Temp } \\
\text { (C) }\end{array}$ & $\begin{array}{c}\text { Intensity } \\
\text { (Cnt/s) }\end{array}$ & $\begin{array}{c}\text { Radius } \\
\text { (nm) }\end{array}$ & $\% P d$ & Mw-R (kDa) & Amp & Baseline \\
\hline & Mean & --- & --- & 25 & $6.1 \mathrm{E} 5$ & 82.3 & 6.9 & $6.2 \mathrm{E} 5$ & 0.4 & 1.04 \\
\hline & $\mathbf{s}$ & --- & --- & 0 & $6.2 \mathrm{E} 4$ & 131.1 & 12 & $2.2 \mathrm{E} 6$ & 0.20 & 0.07 \\
\hline & $\% S$ & --- & --- & 0 & 10 & 159.3 & 166 & 360 & 46.8 & 7.01 \\
\hline & $\mathbf{S}^{2}$ & --- & --- & 0 & $3.9 \mathrm{E} 9$ & 17185.4 & 131 & 4.9E12 & 0.03 & 0.005 \\
\hline & Min & --- & --- & 25 & $5.4 \mathrm{E} 5$ & 29.3 & 0 & $9.1 \mathrm{E} 3$ & 0.3 & 1.00 \\
\hline & Max & --- & --- & 25 & 8.2E5 & 584.6 & 36 & 1.0E7 & 1.0 & 1.30 \\
\hline
\end{tabular}

\begin{tabular}{|c|c|c|c|c|c|c|c|c|c|c|}
\hline \multirow{7}{*}{$\begin{array}{c}\text { PCBA + DBU } \\
+ \\
\text { TTF-C[4]P } \\
\text { Total } \\
\text { concentration } \\
5 \mathrm{mM}\end{array}$} & & Item & $\begin{array}{c}\text { Time } \\
\text { (s) }\end{array}$ & $\begin{array}{c}\text { Temp } \\
\text { (C) }\end{array}$ & $\begin{array}{c}\text { Intensity } \\
\text { (Cnt/s) }\end{array}$ & $\begin{array}{c}\text { Radius } \\
\text { (nm) }\end{array}$ & $\% \mathrm{Pd}$ & Mw-R (kDa) & Amp & Baseline \\
\hline & Mean & --- & --- & 25 & $6.5 \mathrm{E} 5$ & 55.5 & 3.3 & 4.3E4 & 0.3 & 1.01 \\
\hline & $\mathrm{s}$ & --- & --- & 0 & 8.5E4 & 10.8 & 8.2 & 2.3E4 & 0.02 & 0.02 \\
\hline & $\% S$ & --- & --- & 0 & 13 & 19.5 & 246.2 & 55 & 8.1 & 2.14 \\
\hline & $\mathbf{S}^{2}$ & --- & --- & 0 & 7.3E9 & 116.6 & 66.5 & 5.4E8 & 0 & 0 \\
\hline & Min & --- & --- & 25 & 5.3E5 & 48.1 & 0 & $2.9 \mathrm{E} 4$ & 0.3 & 1.0 \\
\hline & Max & --- & --- & 25 & $9.1 \mathrm{E} 5$ & 84.1 & 23.8 & 1.1E5 & 0.3 & 1.07 \\
\hline
\end{tabular}

\begin{tabular}{|c|c|c|c|c|c|c|c|c|c|c|}
\hline \multirow{7}{*}{$\begin{array}{c}\text { PCBA + DBU } \\
+ \\
\text { TTF-C[4]P } \\
\text { Total } \\
\text { concentration } \\
4 \mathrm{mM}\end{array}$} & & Item & $\begin{array}{c}\text { Time } \\
\text { (s) }\end{array}$ & $\begin{array}{c}\text { Temp } \\
\text { (C) }\end{array}$ & $\begin{array}{c}\text { Intensity } \\
\text { (Cnt/s) }\end{array}$ & $\begin{array}{c}\text { Radius } \\
(\mathrm{nm})\end{array}$ & $\% P d$ & Mw-R (kDa) & Amp & Baseline \\
\hline & Mean & --- & --- & 25 & 6.5E6 & 52.5 & 0 & 5.1E4 & 0.07 & 1.03 \\
\hline & $\mathrm{s}$ & --- & --- & 0 & 1.0E6 & 29.0 & 0 & $5.4 \mathrm{E} 4$ & 0.02 & 0.01 \\
\hline & $\% S$ & --- & --- & 0 & 15 & 55.2 & 103.3 & 1.1E2 & 30.76 & 1.56 \\
\hline & $\mathbf{S}^{2}$ & --- & --- & 0 & 1.1E12 & 838.7 & 0 & 3.0E9 & 0.001 & 0 \\
\hline & Min & --- & --- & 25 & 5.0E6 & 0.0 & 0 & 0 & 0 & 1 \\
\hline & Max & --- & --- & 25 & 8.4E6 & 108.6 & 0.1 & 2.0E5 & 0.11 & 1.07 \\
\hline
\end{tabular}

- $[1]=[2]$ 
- Note: TTF-C[4]P and PCBA refer to compounds 1 and 2, respectively.

- Solvent: $o$-dichlorobenzene

Table S3. Mean value from four DLS measurements for the formation and deformation of oligomers by acid/base chemistry (Figure $4 \mathrm{~A})$.

\begin{tabular}{|c|c|c|}
\hline Conditions & Mean Value (nm) & Error (nm) \\
\hline $\mathbf{2}+\mathrm{DBU}$ & 2.5 & 0.5 \\
\hline $\mathbf{2}+\mathrm{DBU}+\mathbf{1}$ & 47.4 & 5.2 \\
\hline $\mathbf{2}+\mathrm{DBU}+\mathbf{1}+\mathrm{MSA}$ & 13.4 & 6.1 \\
\hline
\end{tabular}

Table S4. Mean value from four DLS measurements for concentration dependent studies (Figure 4B).

\begin{tabular}{|c|c|c|}
\hline $\begin{array}{c}\text { Total concentration } \\
([\mathbf{1}]=[2], \mathbf{m M})\end{array}$ & Mean Value $(\mathbf{n m})$ & Error (nm) \\
\hline 4 & 47.4 & 5.2 \\
\hline 5 & 59.1 & 8.0 \\
\hline 10 & 92.8 & 10.5 \\
\hline 20 & 179.8 & 21.6 \\
\hline
\end{tabular}

\section{References}

(1) Nielsen, K. A.; Cho, W. -S.; Jeppesen, J. O.; Lynch, V. M.; Becher, J.; Sessler, J. L. J. Am. Chem. Soc. 2004, 126, 16296-16297.

(2) Hummelen, J. C.; Knight, B. W.; LePeg, F.; Wudl, F.; Yao, J.; Wilkins, C. L. J. Org. Chem. 1995, $60,532-538$.

(3) Jeppesen, J. O.; Takimiya, K.; Jensen, F.; Brimert, T.; Nielsen, K.; Thorup, N.; Becher, J. J. Org. Chem. 2000, 65, 5794-5805

(4) Denuault, G.; Mirkin, M. V.; Bard, A. J. J. Electroanal. Chem. 1991, 308, 27-38.

(5) Hamelin, B.; Jullien, L. J. Chem. Soc. Faraday Trans. 1997, 33, 2153-2160.

(6) Thordarson, P. Chem. Soc. Rev. 2011, 40, 1305-1323.

(7) www.supramolecular.org 